\title{
Assessing the Safety Impacts of Increased Speed Limits on Kansas Freeways
}

\author{
Reza S. Shirazinejad ${ }^{1,2^{*}}$, Sunanda Dissanayake ${ }^{1}$, Ahad Amini Pishro ${ }^{3}$ \\ ${ }^{1}$ Department of Civil Engineering, Kansas State University, Manhattan, USA \\ ${ }^{2}$ Department of Civil and Construction Engineering, Kennesaw State University, Kennesaw, USA \\ ${ }^{3}$ Department of Civil Engineering, Sichuan University, Chengdu, China \\ Email: ^reza s@ksu.edu, sunanda@ksu.edu, ahad.aminipishro@yahoo.com
}

How to cite this paper: Shirazinejad, R.S., Dissanayake, S. and Pishro, A.A. (2019) Assessing the Safety Impacts of Increased Speed Limits on Kansas Freeways. Journal of Transportation Technologies, 9, 56-77. https://doi.org/10.4236/jtts.2019.91004

Received: November 15, 2018

Accepted: December 26, 2018

Published: December 29, 2018

Copyright (c) 2019 by authors and Scientific Research Publishing Inc. This work is licensed under the Creative Commons Attribution International License (CC BY 4.0).

http://creativecommons.org/licenses/by/4.0/

(c) (i) Open Access

\begin{abstract}
Suitable speed limit is important for providing safety for road users. Lower-than-required posted speed limits could cause the majority of drivers non-compliant and higher-than-required posted speed limits may also increase the number of crashes with related severities. The speed limit raised in Kansas from $70 \mathrm{mph}$ to $75 \mathrm{mph}$ on a number of freeway segments in 2011. The goal of this study is to assess the safety impacts of the freeway sections influenced by speed limit increase. Three years before and three years after speed limit increase was considered and three methods were used: 1-Empirical Bayes (EB), 2-before-and-after with comparison group, and 3-cross-sectional study. The Crash Modification Factors (CMFs) were estimated and showed 16 percent increase for total crashes according to EB method. Further, the before-and-after with comparison group method showed 27 percent increase in total crashes and 35 percent increase on fatal and injury crashes. The crosssectional method also presented 25 percent increase on total crashes and 62 percent increase on fatal and injury crashes. It was seen that these increases were statistically significant.
\end{abstract}

\section{Keywords}

Speed Limit Increase, Fatal and Injury Crashes, Freeways, Safety Evaluation, Crash, Modification Factors

\section{Introduction}

The relationship between speed limit and the number of crashes is an important subject to vehicle insurance companies and general public. Proper speed limits provide a safe, consistent, and reasonable speed to protect roadway users. All 
drivers may not like to travel at the same speed and some other drivers may not also understand why the speed limit changes on a roadway segment. Correct speed limits are essential for increasing the safety on highways and streets for any driver who is not familiar with the roadway at all. In 2011, speed limit increased from $70 \mathrm{mph}$ to $75 \mathrm{mph}$ on more than 800 miles of freeways in Kansas. The goal of this study is to assess the safety consequences of the roadways affected by the speed limit increase. Previous research studies that considered the traffic safety effect due to speed limit changes showed significant results as follows.

Speed limit reductions may cause safety issues for drivers and influence crash severity. The safety effects of reducing the speed limit from $90 \mathrm{~km} / \mathrm{h}$ to $70 \mathrm{~km} / \mathrm{h}$ on a number of highways in Belgium was considered. There were sixty-one road sections with a total length of $116 \mathrm{~km}$ and a non-treated group consisted of 19 road sections with a total length of $53 \mathrm{~km}$. Crash data for six years before and six years after speed limit change were considered. The Crash Modification Factor (CMF) was estimated for fatal and injury crashes and showed that speed limit reduction had a decreasing impact on fatal and injury crashes [1]. The safety effect of speed limit reduction from $50 \mathrm{~km} / \mathrm{h}$ to $40 \mathrm{~km} / \mathrm{h}$ for eight urban residential areas in Canada was assessed. Crash data were collected for four years before and four years after speed limit reduction. The Empirical Bayes (EB) and Full Bayesian (FB) methods were utilized to evaluate the safety effectiveness. The FB method results showed that speed limit reduction was effective in reducing crashes and safety for all crash severity types. However, the EB method showed opposite results compared to FB method [2]. A before-and-after study using the Empirical Bayes method was utilized. By considering crash data on some major arterial roads and multilane divided highways for six years before and six years after speed limit decrease from $80 \mathrm{~km} / \mathrm{h}$ to $60 \mathrm{~km} / \mathrm{h}$. The results showed that there was a 7.5 percent reduction in total crashes in Oslo, Norway [3]. Speed limit increase from $55 \mathrm{mph}$ to $65 \mathrm{mph}$ on rural interstates and limited access highways in Illinois was assessed in April 1987. Data were collected for five years before and four years after the speed limit increase. Auto-Regressive Integrated Moving Average models (ARIMA) method for time series data was utilized, which showed the higher speed limit led to 300 more crashes per month in rural areas in Illinois with associated increases in fatal and injury crashes [4]. The speed limit increase from $55 \mathrm{mph}$ to $65 \mathrm{mph}$ on rural interstate highways for the states affected by speed limit increase was considered in 1988. Crash data were collected for five years before and two years after the speed limit increase. The statistical significance was tested by estimating CMF. Finally, the CMF for fatal crashes showed a 26 percent increase compared to other rural roads, and the CMF was even higher when all multilane highways and rural two-lane roads were used and it showed 29 percent increase [5]. The impact of speed limit increase from $55 \mathrm{mph}$ to $65 \mathrm{mph}$ on fatal, Property Damage Only (PDO), and injury crashes was evaluated on Ohio rural interstate highways [6]. Some other 
factors such as weather conditions, time of day, light conditions, season, day of week, and vehicle type were considered for three years before and three years after speed limit increase. Crash data were analyzed by hypothesis testing and passion ratio was used to compare mean crash rates during before-and-after periods. The results showed that the mean fatal crash rate for rural interstate highways had increased. Furthermore, mean injury and Property Damage Only (PDO) crash rates increased as well. The effect of the $65 \mathrm{mph}$ maximum speed limit on Iowa rural interstates was assessed after speed limits increased from $55 \mathrm{mph}$ to $65 \mathrm{mph}$ [7]. Authors tried to check whether a significant change in fatal and major injury crashes could be detected because of speed limit increase or not. The before-and-after comparison group method was carried out for three years before and three years after the speed limit change. Analysis results depicted a 20 percent increase in the number of statewide fatal crashes after the speed limit increase.

The effect of speed limit increase from $65 \mathrm{mph}$ to $70 \mathrm{mph}$ on safety of rural interstate highways in Louisiana was evaluated. A before-and-after study by considering one year before and one year after the speed limit change was employed. It was seen that raising the speed limit on rural interstates made a significant increase in the number of fatal crashes by 37 percent; however, it showed a 10 percent decline in number of injuries [8]. Speed limit increases from $55 \mathrm{mph}$ to $65 \mathrm{mph}$ on urban interstates, two-lane rural highways, and $55 \mathrm{mph}$ to $70 \mathrm{mph}$ on most rural multilane highways in Kansas were evaluated in March 1996. The before-and-after study with comparison group method was utilized to compare the safety impact by considering three years before versus three years after speed limit increases. No statistically significant increase in fatal crashes on rural and urban interstate highways was seen; however, a statistically significant increase in total crashes, fatal crashes, and fatality rates on two-lane rural highways was observed [9]. The speed characteristics before and after the speed limit increases using t-test was analyzed. The results showed that there was statistically significant increase in $85^{\text {th }}$ percentile speed of drivers after speed limit increase compared to before period [10]. The safety effect of multiple roadside treatments in Florida was assessed using Negative Binomial (NB) regression [11]. Roadway characteristics considered were Annual Average Daily Traffic (AADT), segment length, lane width, speed limit, degree of curve, shoulder width, driveway density, density of trees, density of roadside poles per mile, and average distance to trees and poles. It was understood that the AADT and driveway density correlation was very high, as more driveways tend to be a characteristic of high traffic volumes, and speed limit was also statistically significant on fatal and injury crashes. The impact of advertising signs on freeway crashes in Michigan was considered using Negative Binomial (NB) regression model. Some geometric characteristics were considered such as rural or urban area, median type, ramp presence, number of lanes, and some other type of signs located on freeway sections. The results indicated that advertising signs were statistically significant on total 
number of crashes [12]. The crash modification factor was estimated after utilizing NB regression model to check how degree of horizontal curve could affect number of crashes. Roadway segment length, AADT, roadway width, shoulder width, shoulder type, surface type, number of lanes, functional classification, and posted speed limit were selected as explanatory variables and the results showed that the degree of curve and posted speed limit were statistically significant on number of crashes [13]. The effect of road features of two lane rural road networks was examined on crash severity in Italy. For this purpose, NB regression model was employed and lane width, AADT, curvature change rate, section length, and vertical grade were selected as independent variables. It was seen that the vertical grade and AADT were statistically significant on total number of crashes [14].

\section{Data \& Methodology}

The sections affected by speed limit change (treated sections) and without speed limit change (non-treated sections) are identified. The treated group includes all road sections that experienced an increase in the speed limit from $70 \mathrm{mph}$ to 75 $\mathrm{mph}$, and the non-treated group also includes similar set of road sections where the speed limit did not change and remained at $70 \mathrm{mph}$ during the entire time period. The treated and non-treated groups were identified with the assistance from Kansas Department of Transportation (KDOT) and all other data related to each section such as AADT, length of each section, fatal, injury, and PDO crashes were collected from Kansas Crash Analysis and Recording System (KCARS) database for both groups during three years before and three years after speed limit change. In this study, it was decided to consider three years from 2008 to 2010 as the before speed limit change period and three years from 2012 to 2014 as the after speed limit change period, in which the year 2011 is ignored because the speed limit change occurred in that year [15]. Furthermore, several explanatory variables were also considered for all of the treated and non-treated sections. The explanatory variables with their corresponding data sources are listed in Table 1.

In order to evaluate the effectiveness of traffic safety after a certain treatment is implemented, the most common method is a before-and-after study [16], which compares the number of crashes in the before period of a treatment implementation versus after period. There are three basic study designs that are used for safety effectiveness evaluations, which as follows: 1-observational before-and-after studies, 2-observational cross-sectional studies, and 3-experimental before-and-after studies. Observational studies are much more common in road safety than experimental studies, because highway agencies are generally reluctant to use random selection in assigning treatments. For this reason, the focus of this study is on observational studies (AASHTO, 2014). Therefore, a beforeand-after study using the Empirical Bayes (EB) method, a before-and-after study with the comparison group method, and cross-sectional method were all used to evaluate safety by estimating CMFs for speed limit increase. 
Table 1. Explanatory variables with corresponding data sources.

\begin{tabular}{|c|c|c|}
\hline Number & Variable names & Data source \\
\hline 1 & $\mathrm{AADT}$ & \\
\hline 2 & Segment length & \\
\hline 3 & Lane width & \\
\hline 4 & Shoulder width & \\
\hline 5 & Maximum speed limit & \\
\hline 6 & Number of lanes & \\
\hline 7 & Shoulder type & \\
\hline 8 & Surface type & \\
\hline 9 & Functional classification & $\begin{array}{l}\text { Control Section Analysis System } \\
\text { (CANSYS) database }\end{array}$ \\
\hline 10 & Rumble strip presence & \\
\hline 11 & Degree of curve & \\
\hline 12 & Median type & \\
\hline 13 & Median width & \\
\hline 14 & Cross slope & \\
\hline 15 & Area type(rural/urban) & \\
\hline 16 & Presence of curve & \\
\hline 17 & Percentage of heavy vehicle & \\
\hline 18 & International Roughness Index (IRI) & $\begin{array}{l}\text { Pavement Management Information } \\
\text { System (PMIS) database }\end{array}$ \\
\hline 19 & Presence of on or off ramps & Google map \\
\hline 20 & Side friction coefficient & $\begin{array}{c}\text { Kansas Department of Transportation } \\
\text { (KDOT) }\end{array}$ \\
\hline 21 & Access density & KDOT video-logs \\
\hline 22 & Density of trees & Google map \\
\hline 23 & Density of poles/mile & Google map \\
\hline 24 & Roadside Hazard Rating (RHR) & KDOT video-logs \\
\hline 25 & Number of interchanges on freeway segment & Google map \\
\hline
\end{tabular}

\subsection{Before-and-After Study Using EB Method}

Bayesian statistical methods such as Empirical Bayes (EB) method use Bayes' theorem to compute and update probabilities after obtaining new data. Bayes' theorem describes the conditional probability of an event based on data as well as prior information or beliefs about the event or conditions related to the event. Empirical Bayes methods are procedures for statistical inference in which the prior distribution is estimated from the data [17]. In this study, the EB method is utilized to compute the probability of crash occurrence after speed limit increase. The EB method corrects for regression to the mean and traffic volume changes. It is used to estimate the CMF and widely recognized as the state of the art methodology for crash modification factor development, but it depends on the re- 
search area and the appropriate nature of countermeasures [18]. There is a Safety Performance Function (SPF) available for different type of sections. There are several roadway sections, such as two lane roadway, multilane highway, arterial, freeway, and etc. According to Highway Safety Manual (HSM), there is a default SPF for each type of such roadway sections. For example, there is a default SPF for two lane roadways in chapter 10, a default SPF for multilane highway in chapter 11, and a default SPF for freeways in chapter 18. In this study, since all of the sections affected by speed limit change are considered as freeways, and there is no information related to calibration factor for freeway sections, the default SPF for freeways is needed to be used from the Highway Safety Manual (HSM), which is presented in chapter 18 that is related to the predictive method for freeways [19]. SPFs are provided for freeway segments with 4, 6, 8, or 10 through lanes (total of both travel directions). In this study, all of the freeway segments have 4 through lanes of both travel directions.

The base conditions for the SPFs for multiple-vehicle crashes and single-vehicle crashes on freeway segments are utilized according to the section 18.4.2 of chapter 18 in the HSM. The default SPF for the freeway segments is utilized according to Equation (1) [18], which is applied for both single-vehicle crashes and multiple-vehicle crashes based on fatal and injury, and Property Damage Only (PDO) crashes.

$$
N_{S p f, f s, n, m v o r s v, z}=L^{*} \times \exp \left(a+b \times \ln \left[c \times A A D T_{f s}\right]\right)
$$

where,

$N_{S p f, f s, n, m v o r s v, z}=$ predicted average multiple-vehicle crash frequency (mv) or single-vehicle crash frequency (sv) of a freeway segment (fs) with base conditions, $\mathrm{n}$ lanes, and severity; $z(z=f$ i: fatal and injury, PDO: Property Damage Only) (crashes per year);

$L^{*}=$ effective length of freeway segment (mi);

$A A D T_{f s}=$ Annual Average Daily Traffic volume of freeway segment (veh/day); and

$a, b, c=$ regression coefficients $(a, b$, and $c$ coefficients are according to Tables 18-5 and 18-7 included in HSM).

In the EB method, the change in safety for a given crash type at a site is given by Equation (2).

$$
\Delta \text { safety }=B-A
$$

where,

$B$ : The expected number of crashes that would have occurred in the after period without the treatment; and

$A$ : The number of reported crashes in the after period.

In the EB procedure, the SPF is utilized to estimate the number of crashes that would be expected during the before period. The summation of these SPF estimates $(P)$ is combined with the number of crashes $(x)$ in the before period at the treated sites (the sites that were affected by speed limit change) to get an estimate for expected number of crashes $(m)$ before the treatment. This estimate of 
$m$ is according to Equation (3).

$$
m=w_{1}(x)+w_{2}(P)
$$

where the weights $w_{1}$ and $w_{2}$ are estimated as follows:

$$
\begin{gathered}
w_{1}=\frac{p}{p+\frac{1}{k}} \\
w_{2}=\frac{1}{k\left(p+\frac{1}{k}\right)}
\end{gathered}
$$

where,

$k$ : Constant for a given model.

Value of $k$ is estimated from the SPF calibration process. A factor is applied to $m$ to account for the length of the after period and the differences in traffic volumes between before and after periods. This factor is the sum of the annual SPF predictions for the after period divided by $P$, the sum of these predictions for the before period. The result, after applying this factor, is an estimate of $\mathrm{B}$, which is expected number of crashes in the after period without treatment.

The estimate of $B$ is then summed over all road sites in the treated group $\left(B_{\text {sum }}\right)$ and compared with the number of crashes during the after period $\left(A_{\text {sum }}\right)$. The variance (var) of $B$ is also summed over all road sections. The safety effectiveness index $(\theta)$ is estimated as:

$$
\theta=\frac{A_{\text {sum }} / B_{\text {sum }}}{1+\left[\operatorname{var}\left(B_{\text {sum }}\right) / B_{\text {sum }}^{2}\right]}
$$

The standard deviation (SD) of $\theta$ is given by:

$$
S D(\theta)=\left[\frac{\theta^{2}\left\{\left[\operatorname{var}\left(A_{\text {sum }}\right) / A_{\text {sum }}^{2}\right]+\left[\operatorname{var}\left(B_{\text {sum }}\right) / B_{\text {sum }}^{2}\right]\right\}}{\left[1+\operatorname{var}\left(B_{\text {sum }}\right) / B_{\text {sum }}^{2}\right]^{2}}\right]^{0.5}
$$

The percentage change in crashes is $100(1-\theta)$; therefore, any value for $\theta$, indicates a change in number of crashes. The statistical significance of estimated safety effectiveness is assessed according to the following equations [20]:

1) If $\left|\frac{\text { percentage change in crash }}{\text { standard deviation percentage }}\right|<1.7$, treatment effect is not significant at $90 \%$ confidence level.

2) If $\left|\frac{\text { percentage change in crash }}{\text { standard deviation percentage }}\right| \geq 1.7$, treatment effect is significant at $90 \%$ confidence level.

3) If $\left|\frac{\text { percentage change in crash }}{\text { standard deviation percentage }}\right| \geq 2$, treatment effect is significant at $95 \%$ confidence level.

\subsection{Before-and-After Study with Comparison Group Method}

The observational before-and-after evaluation study using the comparison group 
method is also applied in this study, as an alternative evaluation. In this method, the comparison group (non-treated group) plays a significant role in the before-and-after study, since it estimates the change in crash frequency that has happened in the treated group if any treatment has not been made. The comparison group is applied to control for the trends in crash frequency whose causes may be unknown but those affect the crash frequency and crash severity for both treated and non-treated groups equally. On the other hand, the comparison group is also applied to control for Regression To the Mean (RTM), which is the phenomenon where if a variable is extreme on its first measurement, it will tend to be closer to the average on its second measurement, and if it is extreme on its second measurement, it will tend to have been closer to the average on its first according to the HSM. The most important feature of this method is to find the similar type of sections that are geometrically identical to each other. Likewise, the number of vehicles passing the roadway sections. The geometric characteristics for non-treated sections such as shoulder type, degree of curves, median type, median width, number of lanes, lane width, rumble strip type, and cross slope were similar to treated sections. Finally, the geometric characteristic similarity helped to conduct the before-and-after with comparison group method by comparing treated group versus non-treated group. Detailed procedures for performing an observational before-after study with the comparison group method is presented in step-by-step procedure and all steps are listed as follows [19]:

Step 1: The predicted crash frequency is calculated for treated sites during each year of the before and after periods. In this step, the correct Safety Performance Function (SPF) should be utilized. The default freeway SPF for computation according to HSM is included in Equation (8).

$$
N_{S p f, f s, n, m v o r s v, z}=L^{*} \times \exp \left(a+b \times \ln \left[c \times A A D T_{f s}\right]\right)
$$

With,

$$
L^{*}=L_{f s}-\left[0.5 \times \sum_{i=1}^{2} L_{e n, s e g, i}\right]-\left[0.5 \times \sum_{i=1}^{2} L_{e x, \text { seg }, i}\right]
$$

where,

$N_{S p f, f s, n, m v o r s v, z}=$ predicted average multiple vehicle crash frequency (mv) or single vehicle crash frequency (sv) of a freeway segment (fs) with base conditions, $\mathrm{n}$ lanes, and severity $z(z=f$ : fatal and injury, PDO: Property Damage Only) (crashes per year);

$L^{*}=$ effective length of freeway segment (mi);

$L_{f s}=$ length of freeway segment (mi);

$L_{\text {en,seg }, i}=$ length of ramp entrance $\mathrm{i}$ adjacent to subject freeway segment (mi);

$L_{\text {ex }, \text { seg }, i}=$ length of ramp exit i adjacent to subject freeway segment (mi);

$A A D T_{f s}=$ Annual Average Daily Traffic volume of freeway segment (veh/day); and

$a, b, c=$ regression coefficients.

As all of the treated sites are 4 lane freeways, $a, b$, and $c$ coefficients are ac- 
cording to Tables 18-5 and 18-7 included in HSM.

Step 2: The predicted average crash frequency is calculated for each comparison site (non-treated site) in the before and after period and the SPF is based on the site characteristics. There are two different facility types for comparison group sites. Some sites are freeways and the others are rural 4-lane divided highways (non-interstate sections). Two different SPFs should therefore be used. The default SPF for freeways is exactly similar to the treated sites but for the rural multilane highways, the default SPF is based on Highway Safety Manual, which is according to Equation (10).

$$
N_{\text {SPFrd }}=\mathrm{e}^{a+b \times \ln (A A D T)+\ln (L)}
$$

where,

$N_{\text {SPFrd }}=$ predicted average crash frequency for divided multilane highway segment;

$A A D T=$ Annual Average Daily Traffic (vehicles/day) on multilane highway segment;

$L=$ multilane highway segment length (miles); and

$a, b=$ regression coefficients.

The regression coefficients for multilane highways are selected from Table 11-5 in HSM based on total crashes or fatal and injury crashes.

Step 3: The adjustment factor of treated sites in the before period is calculated for each of the non-treated sites in the before period using the equation as follow:

$$
\operatorname{Adj}_{i, j, B}=\frac{N_{\text {predicted }, T, B}}{N_{\text {predicted }, C, B}} \times \frac{Y_{B T}}{Y_{B C}}
$$

where,

$N_{\text {predicted }, T, B}=$ sum of predicted average crash frequencies at treatment site $i$ in the before period using the appropriate SPF and AADT;

$N_{\text {predicted }, C, B}=$ sum of predicted average crash frequencies at comparison site $j$ in the before period using the correct SPF and specific AADT;

$Y_{B T}=$ years of before period for treatment site $i$; and

$Y_{B C}=$ years of before period for comparison site $j$

Step 4: The adjustment factor of treated sites in the after period is calculated for each of the comparison sites in the after period using the following equation:

$$
A d j_{i, j, A}=\frac{N_{\text {predicted }, T, A}}{N_{\text {predicted }, C, A}} \times \frac{Y_{A T}}{Y_{A C}}
$$

where,

$N_{\text {predicted }, T, A}=$ sum of predicted average crash frequencies at treatment site $i$ in the after period using the appropriate SPF and AADT; and

$N_{\text {predicted }, C, A}=$ sum of predicted average crash frequencies at comparison site $j$ in the after period using the correct SPF and specific AADT.

Step 5: The expected crash frequency is calculated in the before period ( $N_{\text {expected } C, B}$ ) for an individual comparison site using the following equation: 


$$
N_{\text {expected }, C, B}=\sum_{\text {All sites }} N_{\text {observed }, C, B} \times A d j_{i, j, B}
$$

Step 6: The expected crash frequency is calculated in the after period ( $N_{\text {expected,C,B }}$ ) for an individual comparison site using the following equation:

$$
N_{\text {expected }, C, A}=\sum_{\text {All sites }} N_{\text {observed }, C, A} \times A d j_{i, j, A}
$$

Step 7: The summation of expected crash frequencies in the before period and after period is calculated for each treated site and comparison site.

Step 8: For each of the treated sites, the comparison ratio of the comparison group is calculated by using the following equation:

$$
r_{i, c}=\frac{N_{\text {expected }, C, A, \text { total }}}{N_{\text {expected }, C, B, \text { total }}}
$$

Step 9: The expected average crash frequency for each of the treated sites without any treatment in the after period is calculated by the equation as follow:

$$
N_{\text {expected }, T, A(\text { without treatment })}=\sum_{\text {All sites }} N_{\text {observed }, B, B} \times r_{i c}
$$

where,

$N_{\text {observed }, B, B}=$ Number of observed crashes for treated sites in the before period.

Step 10: The safety effectiveness, expressed as an odds ratio $\left(O R_{i}\right)$ at an individual treatment site $i$ is calculated by using the following equation:

$$
O R_{i}=\frac{N_{\text {observed }, T, A}}{N_{\text {expected }, T, A(\text { without treatment })}}
$$

where,

$N_{\text {observed,T,A }}=$ Number of observed crashes for treated sites in the after period.

Step 11: The log odds ratio $(R)$ for each of the treated sites is calculated using the following equation:

$$
R_{i}=\ln \left(O R_{i}\right)
$$

Step 12: The weighted adjustment factor $\left(w_{i}\right)$ is calculated for each of the treated sites as follows:

$$
w_{i}=\frac{1}{R_{i(S E)}^{2}}
$$

where,

$$
R_{i(S E)}^{2}=\frac{1}{N_{\text {observed }, T, B, \text { total }}}+\frac{1}{N_{\text {observed }, T, A, \text { total }}}+\frac{1}{N_{\text {Expected }, C, B, \text { total }}}+\frac{1}{N_{\text {Expected }, C, A, \text { total }}}
$$

Step 13: The weighted average log odds ratio $(R)$ across all treated sites is calculated by using the following equation:

$$
R=\frac{\sum_{n} w_{i} R_{i}}{\sum_{n} w_{i}}
$$

Step 14: The overall effectiveness of the treatment expressed as an odds ratio or $\mathrm{CMF}$, averaged across all treated sites is estimated as follows: 


$$
\mathrm{OR}(\mathrm{CMF})=\mathrm{e}^{R}
$$

where,

$R=$ weighted average log odds ratio across all of the treated sites.

Step 15: The overall safety effectiveness index $(\theta)$ is expressed as percentage of change in crashes across all treated sites as follows.

$$
\operatorname{Safety} \text { effectiveness }(\theta)=100 \times(1-\mathrm{OR})
$$

where,

$\mathrm{OR}=$ overall Crash Modification Factor (CMF) across all of the treated sites.

Step 16: The standard error of treatment effectiveness is computed in order to measure the precision of the treatment effectiveness by using the following equation:

$$
\mathrm{SE}(\text { safety effectiveness })=100 \times \frac{\mathrm{OR}}{\sqrt{\sum_{n} w_{i}}}
$$

where,

$\sum_{n} w_{i}=$ total weighted adjustment factor across all of the treated sites

Step 17: The statistical significance of estimated safety effectiveness is assessed by making comparisons with the measure of $\operatorname{Abs}\left(\left|\frac{\text { safety effectiveness }}{\operatorname{SE}(\text { safety effectivenss })}\right|\right)$ and drawing conclusions based on the following criteria [21]:

1) If $\mathrm{Abs}\left(\left|\frac{\text { safety effectiveness }}{\operatorname{SE}(\text { safety effectivenss })}\right|\right)<1.7$, treatment effect is not significant at $90 \%$ confidence level.

2) If $\operatorname{Abs}\left(\left|\frac{\text { safety effectiveness }}{\operatorname{SE}(\text { safety effectivenss })}\right|\right) \geq 1.7$, treatment effect is significant at $90 \%$ confidence level.

3) If $\operatorname{Abs}\left(\left|\frac{\text { safety effectiveness }}{\operatorname{SE}(\text { safety effectivenss })}\right|\right) \geq 2$, treatment effect is significant at $95 \%$ confidence level.

Therefore, 17 steps are required in order to apply the before-and-after study with the comparison group method. Finally, the overall CMF is estimated to evaluate the safety effectiveness of treated sites compared to non-treated sites.

\subsection{Cross-Sectional Study Using Negative Binomial (NB) Regression Model}

Cross-sectional studies use statistical modeling for considering the crash experience of sites with and without a certain treatment and it is commonly referred to as the "with and without study". This method is only available for the time period after implementation of the treatment, and by considering both treatment and non-treatment sites [19]. Unlike the previous two methods, there is no step-by-step methodology for this model, because this model requires model development instead of sequence computations. In order to apply this method, 
all crash, traffic volume, and site characteristics are analyzed in a single model as an indicator variable such as binary variables for the presence or absence of the speed limit increase at a site.

Cross-sectional study was utilized in this study in order to identify several geometric characteristics effect compared to speed limit increase .The Negative Binomial (NB) regression model is the standard approach for modeling the yearly crash frequency based on Highway Safety Manual (HSM) recommendation [19]. This approach is implemented using any of several commercially available software packages. In this research, the STATA statistical software package [22] was utilized to conduct the NB regression and estimate CMF by computing the exponential of treatment factor coefficient. The NB regression approach is commonly used to develop crash prediction models. Considering the number of crashes occurring per year at several intersections in a city. In a Poisson regression model, the probability of intersection $i$ having $y_{i}$ crashes per year is given by Equation (24).

$$
P\left(y_{i}\right)=\frac{\exp \left(-\lambda_{i}\right) \times \lambda_{i}^{y_{i}}}{y_{i} !}
$$

where,

$P\left(y_{i}\right)=$ Probability of intersection $i$, having $y_{i}$ crashes, and

$\lambda_{i}=$ Poisson parameter for intersection $i$, which is equal to intersection $i$ s expected number of crashes per year, $E\left[y_{i}\right]$.

Poisson regression models are estimated by specifying the Poisson parameter $\lambda_{i}$, the expected number of events per period as a function of explanatory variables. For the intersection crash example, explanatory variables may consist of intersection geometric characteristics, signalization, pavement types, visibility, and so forth. The common relationship between explanatory variables and the Poisson parameter is the log linear model according to Equation (25) [21].

$$
\lambda_{i}=\exp \left(\beta X_{i}\right) \text { or, } \ln \left(\lambda_{i}\right)=\beta X_{i}
$$

where,

$X_{i}=$ vector of explanatory variables, and

$\beta=$ vector of estimable parameters.

In the Equation (25), the expected number of crashes per period is given by: $E\left[y_{i}\right]=\lambda_{i}=\exp \left(\beta X_{i}\right)$. This model is estimable by standard maximum likelihood methods, with the likelihood function given by Equation (26) [21].

$$
L(\beta)=\prod_{i} \frac{\exp \left[-\exp \left(\beta X_{i}\right)\right]\left[\exp \left(\beta X_{i}\right)\right]^{y_{i}}}{y_{i} !}
$$

The log likelihood function is easier to manipulate and more appropriate for estimation, and it is given by Equation (27) (Washington et al., 2010).

$$
L L(\beta)=\sum_{i=1}^{n}\left[-\exp \left(\beta X_{i}\right)+y_{i} \beta X_{i}-\ln \left(y_{i} !\right)\right]
$$

In most statistical models, the estimated parameters are utilized to make inferences about the unknown population characteristics thought to impact the 
count process. Maximum likelihood estimates produce Poisson parameters that are consistent, asymptotically normal and asymptotically efficient [21].

A common analysis error is a result of failing to satisfy the property of Poisson distribution that restricts the mean and variance to be equal, when $E\left[y_{i}\right]=\operatorname{VAR}\left[y_{i}\right]$. If this equality does not hold, then the data is said to be under dispersed $\left(E\left[y_{i}\right]>\operatorname{VAR}\left[y_{i}\right]\right)$ or over dispersed $\left(E\left[y_{i}\right]<\operatorname{VAR}\left[y_{i}\right]\right)$, and the parameter vector is biased if corrective measures are not taken. Over dispersion can happen for several reasons and it depends on the phenomenon under investigation. The main reason is that variables influencing the Poisson rate across observations have been omitted from the regression. The Negative Binomial (NB) model is derived by rewriting the Equation (25) such that, for each observation $i$., it would be based on Equation (28) [21].

$$
\lambda_{i}=\exp \left(\beta X_{i}+\varepsilon_{i}\right)
$$

where,

$\exp \left(\varepsilon_{i}\right)=$ Gamma-distributed disturbance term with mean 1 and variance $\propto$.

The addition of this term allows the variance to differ from the mean as shown in Equation (29).

$$
\operatorname{VAR}\left[y_{i}\right]=E\left[y_{i}\right]\left[1+\propto E\left[y_{i}\right]\right]=E\left[y_{i}\right]+\propto E\left[y_{i}\right]^{2}
$$

The Poisson regression model is regarded as a limiting model of the Negative Binomial regression model as $\propto$ approaches zero, which means that the selection between these two models is dependent on the value of $\propto$. The parameter $\propto$ is often referred to as the over dispersion parameter. The Negative Binomial distribution has the form according to Equation (30) [21].

$$
P\left(y_{i}\right)=\frac{\Gamma\left(\left(\frac{1}{\propto}\right)+y_{i}\right)}{\Gamma\left(\frac{1}{\propto}\right) y_{i} !}\left[\frac{\frac{1}{\propto}}{\left(\frac{1}{\propto}\right)+\lambda_{i}}\right]^{\frac{1}{\propto}}\left[\frac{\lambda_{i}}{\left(\frac{1}{\propto}\right)+\lambda_{i}}\right]^{y_{i}}
$$

where,

$\Gamma($.$) = gamma function.$

The Equation (30) results in the likelihood function, which is included in the Equation (31).

$$
L\left(\lambda_{i}\right)=\prod_{i} \frac{\Gamma\left(\left(\frac{1}{\propto}\right)+y_{i}\right)}{\Gamma\left(\frac{1}{\propto}\right) y_{i} !}\left[\frac{\frac{1}{\propto}}{\left(\frac{1}{\propto}\right)+\lambda_{i}}\right]^{\frac{1}{\propto}}\left[\frac{\lambda_{i}}{\left(\frac{1}{\propto}\right)+\lambda_{i}}\right]^{y_{i}}
$$

When the data are over dispersed, the estimated variance term is larger than one would expect under a true Poisson process. As over dispersion gets larger, the estimated variance, and all of the standard errors of parameter estimates become inflated. A test for over dispersion is provided by Cameron and Trivedi (1990) based on the assumption that under the Poisson model, 
$\left(y_{i}-E\left[y_{i}\right]\right)^{2}-E\left[y_{i}\right]$ has mean zero, where $E\left[y_{i}\right]$ is the predicted count $\hat{Y}_{i}$. Therefore, the null and alternative hypothesis are created by:

$$
\begin{gathered}
H_{0}: \operatorname{VAR}\left[y_{i}\right]=E\left[y_{i}\right] \\
H_{A}: \operatorname{VAR}\left[y_{i}\right]=E\left[y_{i}\right]+\propto g\left(E\left[y_{i}\right]\right)
\end{gathered}
$$

where,

$g\left(E\left[y_{i}\right]\right)=$ function of the predicted counts, that is most often given values of $g\left[E\left(y_{i}\right)\right]=E\left(y_{i}\right)$ or $g\left(E\left[y_{i}\right]\right)=E\left[y_{i}\right]^{2}$.

In order to conduct this test, a simple linear regression is estimated based on Equation (32), where $z_{i}$ is regressed on $w_{i}$, where,

$$
Z_{i}=\frac{\left(y_{i}-E\left[y_{i}\right]\right)^{2}-y_{i}}{E\left[y_{i}\right] \sqrt{2}} \text { and } w_{i}=\frac{g\left(E\left(y_{i}\right)\right)}{\sqrt{2}}
$$

After running the regression $\left(Z_{i}=b w_{i}\right)$ with $g\left[E\left(y_{i}\right)\right]=E\left(y_{i}\right)$ and $g\left(E\left[y_{i}\right]\right)=E\left[y_{i}\right]^{2}$, if $b$ is statistically significant in both cases, then $H_{0}$ is rejected for the particular function $g$ [21].

\section{Results}

Three methods have been applied and results of each method are summarized in this section. The results present how total crashes and fatal and injury crashes have changed after speed limit increase according to each method. Further, the statistical significance for each CMF is tested at 95 percent confidence level separately. The Figure 1 presents the fatal, injury, and PDO crashes for both treated and non-treated sections in the before period compared to after period.

It has also been observed that drivers' speed distribution in the before period was different than after period according to some available Automatic Traffic Recorders (ATRs) located at different freeway segments. This information is depicted in Figure 2.

\subsection{EB Method Results}

The safety effectiveness index (CMF) for total crashes is estimated according to the EB method, and it is presented as follows:

$$
\theta=\frac{A_{\text {sum }} / B_{\text {sum }}}{1+\left[\operatorname{var}\left(B_{\text {sum }}\right) / B_{\text {sum }}^{2}\right]}=\frac{1.161}{1+\frac{4536.764}{7638.06^{2}}}=1.160 \text { (total crashes) }
$$

Percentage change in total crashes $=100(1-\theta)=100 \times(1-1.160)=-16$ percent, and the negative sign means that the safety got worse compared to before period. The standard deviation of $\theta$ is also computed according to Equation (7), and its value is written as follows:

$S D(\theta)=0.016$, and the standard deviation percentage is equal to: $100 \times 0.016$ $=1.6$ percent. The statistical significance of the estimated safety effectiveness is assessed based on the equations explained in the methodology section and the final result is presented as follows: 


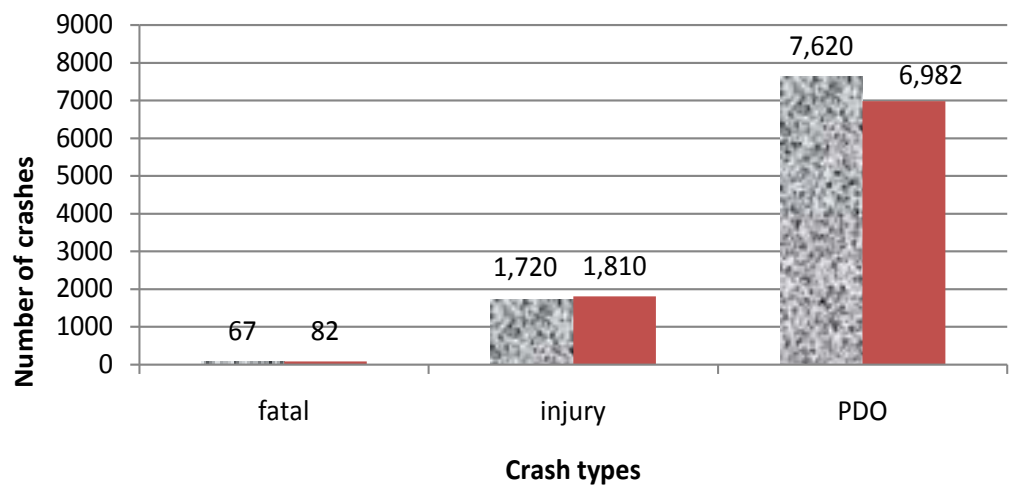

a before

after

(a)

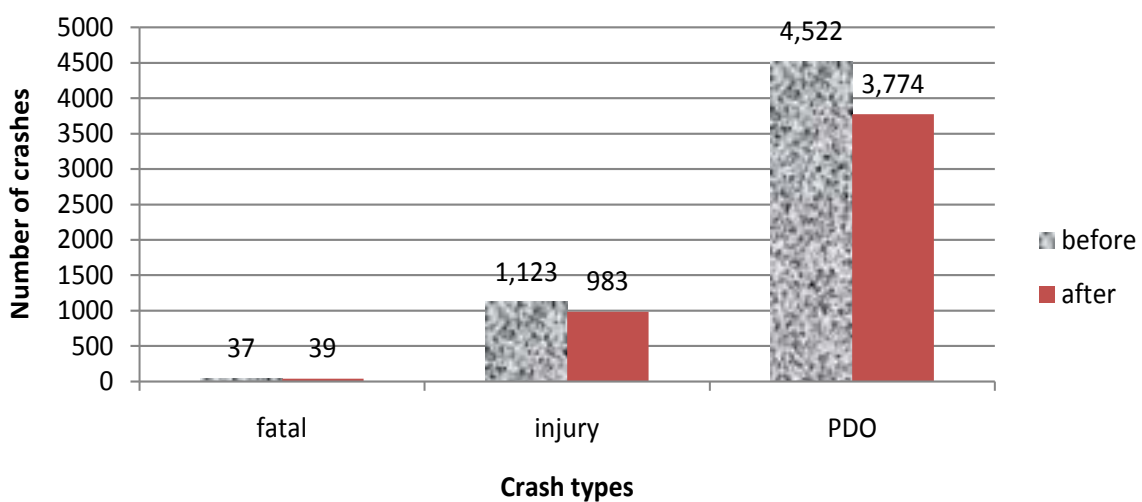

(b)

Figure 1. Observed crashes for treated and non-treated sites during before/after periods. (a) Fatal, Injury, and PDO crashes for treated sections in the before and after periods; (b) Fatal, Injury, and PDO crashes for non-treated sections in the before and after periods.

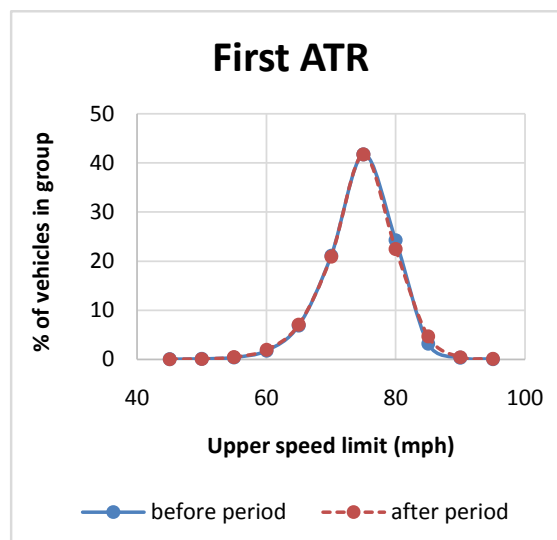

(a)

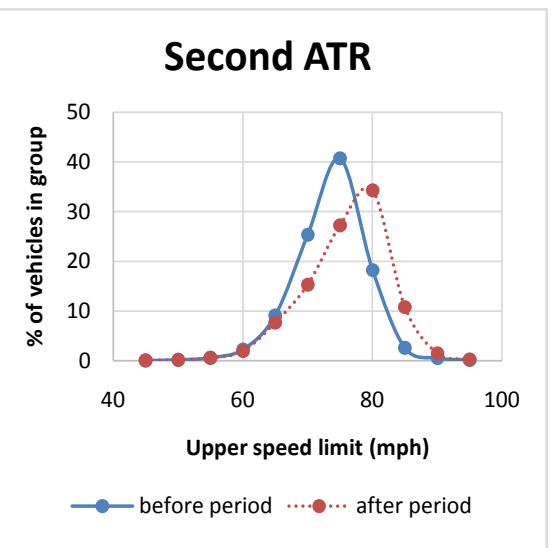

(b)

Figure 2. Sample K-S test distributions for the first two ATRs during before and after periods.

$\left|\frac{\text { percentage change in crashes }}{\text { standard deviation percentage }}\right|=\frac{16}{1.6}=10 \geq 2$, since it is greater than 2 , then the treatment is significant at 95 percent confidence level. The safety effective- 
ness index (CMF) for fatal and injury crashes was also estimated, but there was no statistically significant increase. The following results present the estimated CMF and statistically significant results for fatal and injury crashes.

$$
\theta=\frac{A_{\text {sum }} / B_{\text {sum }}}{1+\left[\operatorname{var}\left(B_{\text {sum }}\right) / B_{\text {sum }}^{2}\right]}=\frac{1.008}{1+\frac{372.141}{1,876.93^{2}}}=1.01 \text { (fatal and injury crashes) }
$$

Percentage change in fatal and injury crashes $=$ $100(1-\theta)=100 \times(1-1.007)=-0.7$ percent. The standard deviation is also computed according to Equation (7), and it is as follows: $S D(\theta)=0.025$. The statistical significance is evaluated according to the criteria listed in the EB method and the result is as follows:

$\left|\frac{\text { percentage change in crashes }}{\text { standard deviation percentage }}\right|=\frac{0.7}{2.53}=0.27<1.7$, treatment effect is not significant at $90 \%$ confidence level.

\subsection{Before-After with Comparison Group Method Results}

The before-and-after study with comparison group method was conducted according to step-by-step procedure as mentioned in the methodology section. The CMFs for both fatal and injury crashes and total crashes are estimated separately. Furthermore, the standard errors for both fatal and injury crashes and total crashes are also computed and the statistical significance of estimated CMFs is assessed according to the criteria listed in step 17 in the Section 2.2. The combined computation results for having the overall CMFs based on total crashes and fatal and injury crashes are summarized in Table 2. Moreover, the statistical significance results at 95 percent confidence level are also specified.

\subsection{Cross-Sectional Study Results}

Two models were estimated based on fatal and injury crashes and total crashes separately. The first model was applied to check whether the speed limit increase has been statistically significant on total number of crashes compared to other geometric characteristics. Same method was followed to examine if the speed limit increase has been statistically significant on fatal and injury crashes. Several independent variables were tested according to Table 1 along with the impact of speed limit variable, and the fatal and injury crashes and total crashes were taken as the dependent variables.

The variables that were not significant were removed from the models, and the models were developed with significant variables along with their coefficients. The CMFs were also estimated by taking the exponential of treatment factor coefficient and the statistical significance test was also considered. This section presents the modeling results for estimating the safety performance functions of treated and non-treated sections in the after period. Figure 3 summarizes the model output for speed limit increase on total number of crashes according to STATA statistical software package [22]. 
Table 2. Combined computation results based on total crashes and fatal and injury crashes.

The weighted average log odds ratio $(R)$ across all treated sites:

$R=\frac{\sum_{n} w_{i} R_{i}}{\sum_{n} w_{i}}=\frac{1005.99}{4187.19}=0.24$ (total crashes), and $R=\frac{\sum_{n} w_{i} R_{i}}{\sum_{n} w_{i}}=\frac{247.69}{814.66}=0.30$ (fatal and injury crashes)

The overall effectiveness of the treatment expressed as an odds ratio or CMF across all sites:

$\mathrm{OR}=\mathrm{e}^{R}=\mathrm{e}^{0.240}=1.27 \quad$ (for total crashes)

$\mathrm{OR}=\mathrm{e}^{R}=\mathrm{e}^{0.304}=1.35 \quad$ (for fatal and injury crashes)

The overall safety effectiveness as percentage of change across all sites $\left(^{*}\right)$ :

Safety effectiveness $=100 \times(1-\mathrm{OR})=100 \times(1-1.271)=-27.12 \% \quad$ (for total crashes)

Safety effectiveness $=100 \times(1-\mathrm{OR})=100 \times(1-1.355)=-35.53 \% \quad$ (for fatal and injury crashes)

The standard error of treatment effectiveness is:

$\mathrm{SE}($ safety effectivenss $)=100 \times \frac{\mathrm{OR}}{\sqrt{\sum_{n} w_{i}}}=100 \times \frac{1.271}{\sqrt{4187.19}}=1.96 \% \quad$ (for total crashes)

$\mathrm{SE}($ safety effectivenss $)=100 \times \frac{\mathrm{OR}}{\sqrt{\sum_{n} w_{i}}}=100 \times \frac{1.355}{\sqrt{814.66}}=4.74 \% \quad$ (for fatal and injury crashes)

The statistical significance of estimated safety effectiveness is assessed as:

$\operatorname{Abs}\left(\left|\frac{\text { safety effectiveness }}{\operatorname{SE}(\text { safety effectivenss })}\right|\right)=\frac{27.12}{1.96}=13.80 \geq 2$, the treatment effect is significant at $95 \%$ confidence level (for total crashes).

$\operatorname{Abs}\left(\left|\frac{\text { safety effectiveness }}{\operatorname{SE}(\text { safety effectivenss })}\right|\right)=\frac{35.53}{4.74}=7.49 \geq 2$, the treatment effect is significant at $95 \%$ confidence level (for fatal and injury crashes).

Note: $\left.{ }^{*}\right)$ The negative estimate of the safety effectiveness indicates a negative effectiveness, i.e., 27 percent increase in total crashes and 35 percent increase for fatal and injury crashes.

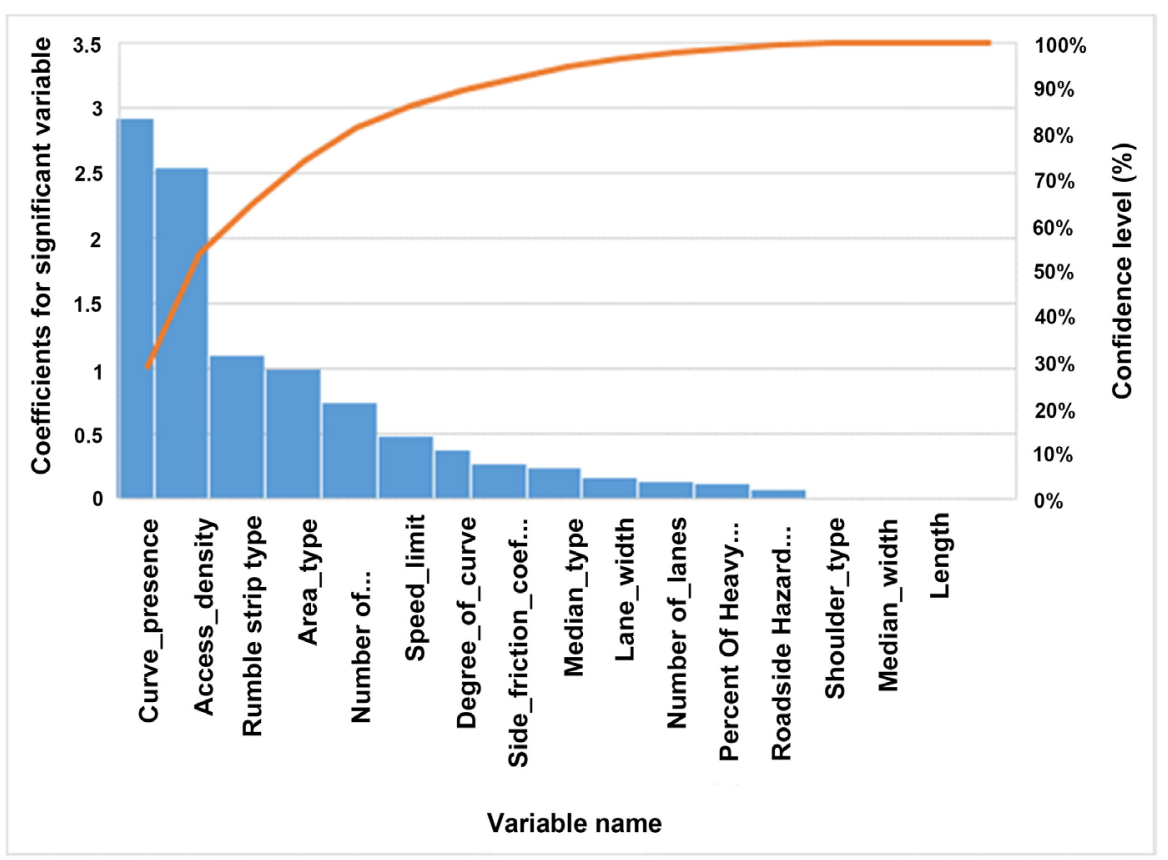

Figure 3. Negative binomial regression for total crashes. 
According to Figure 3, the speed limit was statistically significant and the regression model was developed with the rest of all other significant variables and is shown in Equation (33).

$$
\mathrm{y}=\mathrm{e}^{3.60+(0.000043 \times \mathrm{ADT})+(0.042 \times L)+(0.228 \times S)+(0.680 \times i)+(0.061 \times \mathrm{PHV})+(0.663 \times a)+(0.090 \times c)}
$$

where,

$y=$ Total number of crashes;

ADT = Average Daily Traffic;

$L=$ Segment length;

$S=$ Maximum speed limit;

$I=$ Number of interchanges;

$\mathrm{PHV}=$ Percentage of heavy vehicle;

$A=$ Area type; and

$C=$ Curve presence.

There are some variables that have negative sign and this means that they have a decreasing impact on total number of crashes and those that have the positive sign, it means that they have an increasing impact on total number of crashes. In order to understand if the Negative Binomial (NB) regression model is the best method for cross-sectional study, it is important to identify if there is any over dispersion in the available data. Since the NB model is used if over dispersion exists in the data and as in this study the variance value (4135.38) is far exceeds the mean (69.04), over dispersion exists in the data and; therefore, the NB model is suitable for this type of data [23]. The CMF is also estimated according to Equation (34).

$$
\mathrm{CMF}=\exp (C V)
$$

where,

$C=$ coefficient of the treatment effect (speed limit increase) $=0.228$; and

$V=$ Value at which one needs the $\mathrm{CMF}=1$ (when the improved speed limit of $75 \mathrm{mph}$ is present).

The $\mathrm{CMF}$ is computed as, $\mathrm{CMF}=\exp (0.228 \times 1)=1.25$. The estimated CMF of 1.25 is greater than one and presents that speed limit increase has caused 25 percent increase on total number of crashes. Similarly, the second model is developed for fatal and injury crashes by following a similar procedure. Figure 4 summarizes the regression model results for the fatal and injury crashes.

According to Figure 4, the speed limit increase was also statistically significant on fatal and injury crashes. The regression model is developed for all other independent significant variables and the model summary result is included in Equation (35).

$$
y=\mathrm{e}^{-2.18+(0.00038 \times \mathrm{ADT})+(0.045 \times L)+(0.485 \times S)+(0.373 \times D)+(0.748 \times i)+(0.121 \times \mathrm{PHV})+(0.997 \times a)+(2.92 \times c)+(2.54 \times \mathrm{AD})}
$$

where,

$$
\begin{aligned}
& y=\text { Fatal and injury crashes; } \\
& \text { ADT = Average Daily Traffic; }
\end{aligned}
$$




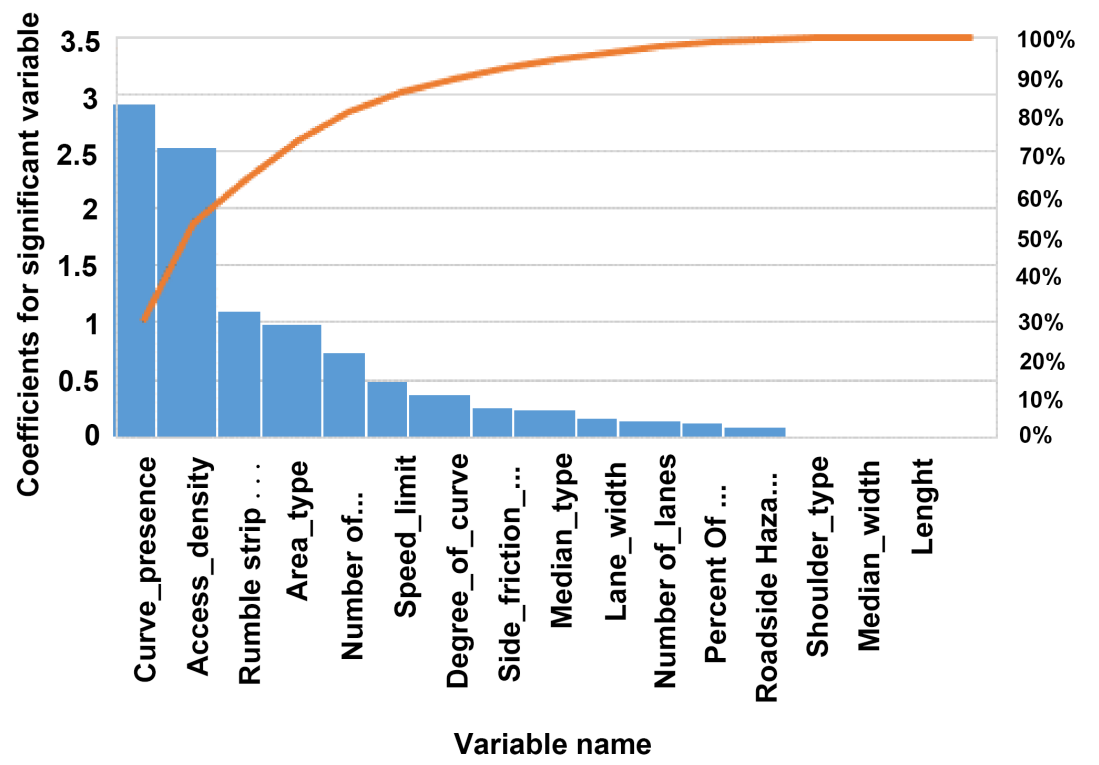

Figure 4. Negative Binomial Regression for fatal and injury crashes.

$L=$ Segment length;

$S=$ Maximum speed limit;

$D=$ Degree of curve;

$I=$ Number of interchanges;

$\mathrm{PHV}=$ Percentage of heavy vehicle;

$A=$ Area type;

$c=$ Curve presence; and

$\mathrm{AD}=$ Access density.

In this study, the variance value of cross sectional model for fatal and injury crashes is 2430 and it very far exceeds the mean (44.15). Therefore, the over dispersion exists in the data, and the NB model is also suitable for this type of data according to fatal and injury crashes. The CMF for fatal and injury crashes is estimated according to Equation (34) and the final result is as follows.

$\mathrm{CMF}=\exp (0.485 \times 1)=1.62$, and the estimated CMF of 1.62 is greater than one, which presents that speed limit increase has caused 62 percent increase on fatal and injury crashes.

\section{Conclusions and Discussion}

Three safety effectiveness methods were conducted in this study. Before-andafter study using the EB method, before-and-after study with the comparison group method, and the cross-sectional study, each method estimated different CMFs for total crashes and fatal and injury crashes. Summary results for each method are presented in Table 3 with the estimated CMFs and the corresponding Standard Errors (SE).

The EB method presented 16 percent increase for total crashes but there was no increase for fatal and injury crashes. The before-and-after with comparison group method showed that raising speed limit caused 27 percent increase in total 
Table 3. Estimated CMFs for total crashes and fatal and injury crashes.

\begin{tabular}{|c|c|c|c|c|}
\hline \multirow{2}{*}{ Method } & \multicolumn{2}{|c|}{ Fatal and injury crashes } & \multicolumn{2}{|r|}{ Total crashes } \\
\hline & $\mathrm{CMF}$ & Standard Error (SE) & $\mathrm{CMF}$ & Standard Error (SE) \\
\hline $\begin{array}{l}\text { 1) Before-and-after with } \\
\text { EB method }\end{array}$ & 1.01 & 0.025 & 1.16 & 0.016 \\
\hline $\begin{array}{l}\text { 2) Before-and-after with } \\
\text { comparison group method }\end{array}$ & 1.35 & 0.047 & 1.27 & 0.019 \\
\hline 3) Cross-sectional method & 1.62 & 0.244 & 1.25 & 0.112 \\
\hline
\end{tabular}

number of crashes and even higher increase for fatal and injury crashes, which was 35 percent increase after speed limit increased. Furthermore, several geometric characteristics were considered along with speed limit variable based on cross-sectional method. The results presented that speed limit increase was statistically significant on total crashes and fatal and injury crashes. The estimated CMFs through cross-sectional method presented that speed limit increase caused 25 percent increase in total crashes and 62 percent increase on fatal and injury crashes. The estimated CMFs were statistically significant at 95 percent confidence level according to the three applied methods except for the results related to fatal and injury crashes of EB method, which was not significant at 95 percent confidence level. In addition, the highest CMF for fatal and injury crashes was estimated according to cross-sectional method, which showed a 62 percent increase after speed limit increased. In summary, the EB method only considers treated sites and the models developed for cross-sectional method do not explain crash outcomes completely and only considers the after period. Therefore, among the three applied methods, the before-and-after with comparison group method results are more reliable than other methods, since it contains information about both treated and non-treated sites and it also considers both before and after periods [20]. In addition, the SPFs utilized in the EB method and before-and-after with comparison group methods were the default SPFs included in HSM and there were no available calibration factors for Kansas. It would be ideal to develop a new SPF for freeway segments specifically for state of Kansas in the future.

\section{Acknowledgements}

This project was supported by K-TRAN program of the Kansas Department of Transportation and the authors wish to acknowledge the assistance provided by the project monitor, Mr. Steven Buckley. Authors also wish to thank Ms. Tina Cramer for providing the data needed for conducting this study.

\section{Conflicts of Interest}

The authors declare no conflicts of interest regarding the publication of this paper.

\section{References}

[1] De Pauw, E., Daniels, S., Thierie, M. and Brijs, T. (2014) Safety Effects of Reducing 
the Speed Limit from $90 \mathrm{~km} / \mathrm{h}$ to $70 \mathrm{~km} / \mathrm{h}$. Accident Analysis \& Prevention, 62, 426-431. https://doi.org/10.1016/j.aap.2013.05.003

[2] Islam, M.T. and El-Basyouny, K. (2015) Full Bayesian Evaluation of the Safety Effects of Reducing the Posted Speed Limit in Urban Residential Area. Accident Analysis \& Prevention, 80, 18-25. https://doi.org/10.1016/j.aap.2015.02.026

[3] Elvik, R. (2013) A Before-After Study of the Effects on Safety of Environmental Speed Limits in the City of OSLO. Norway. Safety Science, 55, 10-16. https://doi.org/10.1016/j.ssci.2012.12.007

[4] Rock, S.M. (1995) Impact of the 65 mph Speed Limit on Accidents, Deaths, and Injuries in Illinois. Accident Analysis \& Prevention, 27, 207-214. https://doi.org/10.1016/0001-4575(94)00058-T

[5] Baum, H.M., Wells, J.K. and Lund, A.K. (1990) Motor Vehicle Crash Fatalities in the Second Year of $65 \mathrm{mph}$ Speed Limits. Journal of Safety Research, 21, 1-8. https://doi.org/10.1016/0022-4375(90)90042-A

[6] Pant, P.D., Adhami, J.A. and Niehaus, J.C. (1992) Effects of the 65-mph Speed Limit on Traffic Accidents in Ohio. Transportation Research Record, 1375, 53-60.

[7] Ledolter, J. and Chan, K.S. (1996) Evaluating the Impact of the 65mph Maximum Speed Limit on Iowa Rural Interstates. The American Statistician, 50, 79-85.

[8] Schneider, H. (2001) An Analysis of the Impact of Increased Speed Limits on Interstates and on Highways in Louisiana. No. HS-809 367.

[9] Najjar, Y.M., Stokes, R.W., Russell, E.R., Ali, H.E. and Zhang, X.B. (2000) Impact of New Speed Limits on Kansas Highways. Kansas Department of Transportation, Topeka, KS, No. K-TRAN: KSU-98-3.

[10] Shirazinejad, R.S. and Dissanayake, S. (2018) Analysis of Speed Characteristics before and after Speed Limit Change. Transportation Research Board 97 th Annual Meeting, Washington, D.C., No. 18-05148.

[11] Park, J. and Abdel-Aty, M. (2015) Assessing the Safety Effects of Multiple Roadside Treatments Using Parametric and Nonparametric Approaches. Accident Analysis \& Prevention, 83, 203-213. https://doi.org/10.1016/j.aap.2015.07.008

[12] Shirazinejad, R.S. and Al-Bayati, A.J. (2018) Impact of Advertising Signs on Freeway Crashes within a Certain Distance in Michigan. Proceedings Construction Research Congress Proceedings, New Orleans, LA, 698-705.

https://doi.org/10.1061/9780784481288.068

[13] Gooch, J.P., Gayah, V.V. and Donnell, E.T. (2016) Quantifying the Safety Effects of Horizontal Curves on Two-Way, Two-Lane Rural Roads. Accident Analysis \& Prevention, 92, 71-81. https://doi.org/10.1016/j.aap.2016.03.024

[14] Russo, F., Busiello, M. and Dell'Acqua, G. (2016) Safety Performance Functions for Crash Severity on Undivided Rural Roads. Accident Analysis \& Prevention, 93, 75-91. https://doi.org/10.1016/j.aap.2016.04.016

[15] Høye, A. (2015) Safety Effects of Section Control-An Empirical Bayes Evaluation. Accident Analysis \& Prevention, 74, 169-178. https://doi.org/10.1016/j.aap.2014.10.016

[16] Elvik, R. (2002) The Importance of Confounding in Observational before-and-after Studies of Road Safety Measures. Accident Analysis \& Prevention, 34, 631-635. https://doi.org/10.1016/S0001-4575(01)00062-8

[17] Glickman, M.E. and Van Dyk, D.A. (2007) Basic Bayesian Methods. In: Ambrosius, W.T., Ed., Topics in Biostatistics, Humana Press, New York, 319-338. https://doi.org/10.1007/978-1-59745-530-5_16 
[18] Gross, F., Lyon, C., Persaud, B. and Srinivasan, R. (2013) Safety Effectiveness of Converting Signalized Intersections to Roundabouts. Accident Analysis \& Prevention, 50, 234-241. https://doi.org/10.1016/j.aap.2012.04.012

[19] AASHTO (2014) Highway Safety Manual. Volume 1. American Association of State Transportation Officials, Washington DC.

[20] AASHTO (2014) Highway Safety Manual. Volume 3. American Association of State Transportation Officials, Washington DC.

[21] Washington, S.P., Karlaftis, M.G. and Mannering, F. (2010) Statistical and Econometric Methods for Transportation Data Analysis. CRC Press, Boca Raton.

[22] Stata Corp. (2015) Stata Statistical Software. Stata Corp., College Station, TX.

[23] Hilbe, J.M. (2011) Negative Binomial Regression. Cambridge University Press, Cambridge. https://doi.org/10.1017/CBO9780511973420 